\title{
Quality challenges to the universities for contributing to the development of the smart cities and communities
}

\author{
Juhani Anttila, Academician, M.Sc. (Electrical Engineering) \\ International Academy for Quality (IAQ) \\ E-mail: juhani.anttila@telecon.fi, www.QualityIntegration.biz \\ Kari Jussila, M.Sc. (Physical Electronics), M.Sc. (Economics) \\ University of Helsinki \\ E-mail: kari.jussila@aalto.fi
}

\begin{abstract}
Universities have had a diverse influence on the development of the society as a whole and also today on the smart city and community projects. Successful collaboration with the many different involved societal parties, however, sets requirements forquality in all of the main activity sectors of the universities including higher education, research and participation and influence in regional development. In practice, this is ensured through organizational learning towards excellence in the overall performance of the university that implies professional quality management principles, innovations in processes and practices aligned with the other organizations of the society.

Smart cities and communities bring together city planning, industry, universities and citizens to improve urban life of individuals and organizations and ultimately to enhance quality of society and reinforcing sustainable development. Smart city also is a manifestation of the $4^{\text {th }}$ industrial revolution and industry 4.0, which are the subjects of considerable discourse today widely.These emerging phenomena imply innovations, better planning, a more participatory approach, higher energy efficiency, better transport solutions, intelligent use of information and communication technologies. However, it is essential that people are at the center.

This article brings up conceptual bases, practical solutions and examples especially from the viewpoint of professional quality management in the universities.
\end{abstract}

Key words: higher education, university, smart city, digitalization, quality, excellence, quality management, organizational learning

\section{Universities in the smart urban quality development}

This article deals with the arguments and means for striving for high quality in the universities. This is especially justified as a prerequisite for the universities' successful contributions to the development of the smart cities or communities. Also in general, the importance of high quality is emphasized ${ }^{1}$ in the higher education.

Almost one thousand ranked universities ${ }^{2}$ exist in different cities all over the world; the bigger cities typically have several or many universities. However, the academic university rankings are mainly directed to emphasize the academic achievements and do not follow the traditional recognized quality concepts or principles. Hence, the universities have much to learn and develop with regard to the professional quality

\footnotetext{
${ }^{1}$ ESG (2015). Standards and guidelines for quality assurance in the European higher education area, EURASHE, Brussels, Belgium. http://www.eua.be/Libraries/quality-assurance/esg_2015.pdf?sfvrsn=0

${ }^{2}$ Times Higher Education (2017). World university rankings 2016-2017, https://www.timeshighereducation.com/worlduniversity-rankings/2017/world-ranking\#!/page/0/length/25/sort_by/rank/sort_order/asc/cols/stats
} 
practices. Particularly this can happen in collaboration with the other organizations, which they also are serving in the society.

Universities are essentially urban institutions. Modern universities were born and developed from the year of $859^{3}$ onwards in the cities and on their impact, and in turn, they have influenced on the evolution of the cities. Universities play a significant role in supporting regional social cohesion, economic growth and future competitiveness. Given the desire to become increasingly knowledge-based, as is the situation with regard to the smart city development, the higher education is an essential component of socio-economic and cultural development. Many universities or their researchers have been involved and collaborated with other organizations in the smart city development projects, which have been carried out in various countries since 2011.

Smart cities aim at innovatively fulfilling the operating and living needs and expectations of the people and organizations with the smart urban infrastructure and services. Smart cities are intentionally greener, safer, faster and friendlier than the traditional ones. Hence ultimately the smart cities strive for the sustainable development ${ }^{4}$ and the quality of society.

The authors have defined the high quality society as a good, well-functioning, welldeveloping, or excellent society for all the interested parties involved, and they have elaborated the quality of society in details in other articles ${ }^{56}$. Quality of society is a new challenge to the smart city development, because in the societal context, quality is not accustomed to be dealt with in the comprehensive and systematic way by using a professional quality approach. Quality of society is based on the quality of the organizations in the society, including involved university actors, and the results from their achievements and collaborative learning, and hence the quality of the smart city evolves by diffusing. In this article, our main focus is on the quality of the universities and particularly in the context of their smart city involvement. The authors have conceptualized the professional quality and quality management in general in another article $^{7}$. Many organizations involving with the smart city development or operation are small organizations (SMEs) or startups. However, no established quality methodologies are available yet for those organizations ${ }^{8}$.

Traditionally universities are active in three merged dimensions: (a) The highest level of education, (b) academic research and dissemination of the research results, and (c) partnership and collaboration with the surrounding society including education, training, research and development projects with public and private organizations. Especially innovations play a significant rolein this context. Quality and innovation are closely related partnering disciplines ${ }^{9}$. Contribution to the smart city development is a serious challenge to the universities, and in this context all the dimensions of the university activities should be considered together, because theyall are organically involved in the smart city development. Fundamentally, universities

\footnotetext{
${ }^{3}$ Arbaoui, L. (2012). Al Karaouin of Fez (Morocco): The oldest university in the world, Morocco World News, https://www.moroccoworldnews.com/2012/10/59056/al-karaouin-of-fez-the-oldest-university-in-the-world/

${ }^{4}$ United Nations, General Assembly (2015). Resolution adopted by the General Assembly on 25 September 2015, Transforming our world: the 2030 Agenda for sustainable development, A/RES/70/1. http://www.un.org/ga/search/view_doc.asp?symbol=A/RES/70/1\&Lang=E.

${ }^{5}$ Anttila, J. and Jussila, K. (2015). Societal quality and competitiveness, The 15th International Symposium on Quality in Opatija, Croatia.

${ }^{6}$ Anttila, J. and Jussila, K. (2015). Striving for the 'Quality society' through high quality education and lifelong learning, 59th

EOQ Congress, Athens, Greece.

${ }^{7}$ Anttila, J. and Jussila, K. (2017). Understanding quality - Conceptualization of the fundamental concepts of quality (To be published).

${ }^{8}$ Anttila, J. and Jussila, K. (2017). Out of the crisis of the quality profession: The new renaissance in the quality discipline (To be published).

${ }^{9}$ Anttila, J. and Jussila, K. (2017). Striving for benefits of sustainability from the interactivity of quality and innovation (To be published).
} 
are intelligent, i.e. cognitive thinking, centers, and hence for instance, according to the Rector of Tallinn University, Estonia, 'to contribute more to the society, we have set the goal of becoming the promoter of intelligent lifestyle in Estonia. The term Intelligent Lifestyle stands for making research based decisions in order to improve the society in general and well-being of its citizens. ${ }^{10}$ This is the unique strength of the universities in contributing to the development of smart cities ${ }^{11}$, too.

Smart city ${ }^{1213}$ is not a clear concept, and it has no consistent definition among practitioners and academia. A proposed definition ${ }^{14}$ is that smart city is a term denoting the effective integration of physical, digital and human systems in the built environment to deliver a sustainable, prosperous and inclusive future for its citizens. Hence, smart city also is a manifestation of the $4^{\text {th }}$ industrial revolution ${ }^{15}$ and industry $4.0^{16}$, which are currently the subject of discussions in the international fora. The smart city phenomenon has its roots in the digitization (the conversion of analogue data into digital form) from the late $17^{\text {th }}$ century and its modern consequence digitalization (the adoption of digital technology by an organization, industry, country, etc.) from the mid $1950 \mathrm{~s}^{1718}$. The smartness of the cities or society is a broad and fuzzy issue and a never-ending and emergent process towards the smart, smarter and smartest societal environments. The smart city has no clear borders with the surrounding society, and it is in a continuous interaction with the actors outside the smart city area. At least implicitly, it is assumed that the smart cities will have the positive effect on the quality of the society as a whole. On the other hand also the overall development of society influences on the smart city development.

In a practical way, a smart city is a place where traditional networks and services are made more flexible, efficient, and sustainable with the use of information, digital and telecommunication technologies, to improve the operations for the benefit of the people and organizations in the city. The different components of the smart city include smart citizen, smart governance, smart education, smart security, smart healthcare, smart building, smart infrastructure, smart transportation, smart mobility, smart energy, and smart technology ${ }^{19}$. Digitalization, and information and communication technology are the main enabling keys to transform traditional cities to smart cities. For instance, the 5G mobile networks, which are right now under development, are needed for instance for smart transportation, and the closely related emerging technological trends, Internet of things (IoT), Big data, Artificial intelligence (AI) and Intellectual robotics, and Blockchain, provide many unlimited opportunities for the development of the smart cities.

Because smart cities are very much based on information, also information security is a core topic in the context of the smart cities. This includes the comprehensive

\footnotetext{
${ }^{10}$ Land, T. (2016). Presentation of the Rector of Tallinn University, ARENE meeting in Tallinn in November 2016 (From T. Kekäle).

${ }^{11}$ Deakin, M. and Al Waer, H. (2011). From intelligent to smart cities, Intelligent Buildings International 3, pp. 133-139. http://www.tandfonline.com/doi/pdf/10.1080/17508975.2011.586673?needAccess=true.

${ }^{12}$ Mohanty, S., Choppali, U. and Kougianos, E. (2016). Everything you wanted to know about smart cities, IEEE Consumer Electronics Magazine Vol. 5, Issue 3, http://ieeexplore.ieee.org/document/7539244/.

${ }^{13}$ ISO/IEC JTC 1 (2015). Smart cities, ISO Geneva Switzerland,

https://www.iso.org/files/live/sites/isoorg/files/developing_standards/docs/en/smart_cities_report-jtc1.pdf

${ }^{14}$ Ibid.

${ }^{15}$ Schwab (2016). The Fourth Industrial Revolution: What it means, how to respond

${ }^{16}$ European Parliament (2016). Directorate General for internal policies. Policy Department A. Economic and scientific polity.

Industry 4.0.

${ }^{17}$ Brennen, S. and Kreis, D. (2014). Digitalization and digitization, http://culturedigitally.org/2014/09/digitalization-and-

digitization/.

${ }^{18}$ Snabe, J. (2015). What will digitalization do to the future? https://www.weforum.org/agenda/2015/11/what-will-digitalizationdo-to-the-future/.

${ }^{19}$ Frost\& Sullivan (2013). Strategic opportunity analysis of the global smart city market, http://www.egr.msu.edu/ aesc310web/resources/SmartCities/Smart\%20City\%20Market\%20Report\%202.pdf.
} 
knowledge area of privacy management (a human focus), information security management (an organizational focus) and cybersecurity management (a society focus $)^{20}$, are competence areas required by all partners involved with the development and operation of the smart cities. Needs for expertise in these areas is very big in many different organizations, especially in SMEs, involved with the smart city projects, and hence this is an important educational challenge to the universities.

Urban societies are 'scale-free networks' ${ }^{21}$, and hence smart city development is a diffusion process from the activities and achievements of many different independent private companies, public service organizations and institutions and influential individuals. Universities are among those actors. Smart city development is seen as a very big financial effort; the estimated smart city market is likely to be worth of a cumulative $\$ 1.5$ Trillion by $2020^{22}$.

A lot of smart city researches have been made and related reports are available, standardization activities are going on, hundreds of practical implementations are in progress all over the world, smart city conferences and Expos have taken place, and even a global smart city award competitions have been arrangedannually. Right now smart city development is still in its beginning phase, and cities have started their projects within restricted parts of the cities or with some particular smart objects and targets. In Finland we have smart city projects in six cities. In the Helsinki metropolitan area we have smart city projects in three neighboring cities, Helsinki, Espoo and Vantaa ${ }^{2324}$, from which we have some examples in this article. These cities have in their projects mutual cooperation, and collaboration with the local and foreign universities. Hundreds of universities all over the world have reported their involvements and contributions in different ways in various smart city projects.Some universities have implemented smart campuses within their universities ${ }^{25}$.

\section{Excellence in the university quality performance}

Quality is imperative in all educational institutions ${ }^{26}$ but especially its importance is emphasized in all of the three different activities of universities including the composite activities of education, research and societal collaboration. The university should strive for excellent performance ${ }^{27}$ throughout the university activities by using in a creative way the general professional quality management approach including recognized quality management principles and practices ${ }^{28}$ that are used in all kinds of organizations of the society. Only excellence can ensure sustained success.

Quality of the university activities is an extensive multidimensional challenge. Universities are multi-faculty entities, and especially services to the companies and other organizations of the society set severe quality requirements. In fact, universities should be pioneers or at least 'Primus inter pares' in their quality approach.

\footnotetext{
${ }^{20}$ Anttila, J. and Jussila, K. (2016). Challenges for the comprehensive and integrated information security management, Introduction to the panel discussion at the ARES Conference, Salzburg Austria.

${ }^{21}$ Barabási, A. (2003). Linked: How everything is connected to everything else and what it means for business, science, and everyday life. Plume Books. New York USA.

${ }^{22}$ Frost \& Sullivan, Strategic opportunity analysis of the global smart city market, http://www.egr.msu.edu/ aesc 310-

web/resources/SmartCities/Smart\%20City\%20Market\%20Report\%202.pdf.

${ }^{23}$ Forum Virium Helsinki (2017). Kalasatama Smart City district of Helsinki (as an example from Finland), https://fiksukalasatama.fi/en/smart-city/.

${ }^{24}$ Lappalainen, P., Markkula, M. and Kune, H. (Eds.) (2015). Orchestrating regional innovation ecosystems - Espoo innovation garden, https://urbanmillblog.files.wordpress.com/2015/04/eka_final_cover_hires.pdf.

${ }^{25}$ The University of Glasgow (2017). World changing campus, http://www.gla.ac.uk/about/campus/overview/smartcampus/.

${ }^{26}$ UNESCO. Education for all, The quality imperative, 2005. http://unesdoc.unesco.org/images/0013/001373/137333e.pdf.

${ }^{27}$ NIST (National Institute for Standards and Technology). Baldrige Excellence Framework (Education), 2015.

https://www.nist.gov/baldrige/publications/baldrige-excellence-framework/education.

${ }^{28}$ ISO (2015). ISO 9000 Quality management systems - Fundamentals and vocabulary, ISO, Geneva, Switzerland.
} 
Universities should not be isolated institutions. It is not enough that the universities only follow the quality references of the education sector but also the best general professional business references applied in the other organizations of the society should be taken seriously. Quality is a global issue and it applies to all business sectors. Harmonized quality concepts, principles, and practices are foundations of the professionalism and support collaboration.

The term 'performance excellence' in the context of universities refers to an integrated quality approach within the management and operations of the university and its units, which results in (a) the delivery of ever-improving value to the stakeholders and contributing to organizational sustainability, (b) the improvement of overall organizational effectiveness and capabilities, and (c) the organizational and personal learning ${ }^{29}$. Competitive advantages of the universities can be very versatile.

Faculties, institutes or other specialized units of the universities may be very different, and they also may be at different development stages. Hence, those units also should have different quality management approaches. When dealing with the quality management in the universities, one should consider both the university (the university corporation) as a whole and all its different operational units. In this article the general word organization is used in this context to mean the whole university or its single units.

Successful excellent operation requires surpassing challenging references and continual organizational learning. This includes:

- Exceeding organization's own performance goals and targets.

- Succeeding in organizational performance within own academic branch in average and being among the best reference universities.

- Evidencing world class performance, including benchmarks and best practices among other organizations of the society outside the university sector.

Hence, performance excellence represents the highest level of quality in an organization.

The overall performance of the organization is a broad concept including four main categories of performance $^{30}$ :

- Stakeholder-focused performance: Organization's performance seen by its stakeholders or interested parties ${ }^{31}$.

- Operational performance: Organization's internal performance including hard process performance (for example cost efficiency, throughput or lead time) and soft performance (for instance workforce skills).

- Product performance: Characteristics of the products including goods and services $^{32}$. The products of universities are mainly services.

- Financial and market performance: Operational costs, productivity, competitiveness, and market share, etc. Also universities compete with other educational institutions globally.

\section{Conceptual, methodological and organizational challenges}

The educational sector is in a paradox situation with regard to quality. The absolute importance of quality is highlighted in the speeches and writings but its professional

\footnotetext{
${ }^{29}$ NIST (National Institute for Standards and Technology) (2014). Baldrige Excellence Framework,. http://www.nist.gov/baldrige/publications/business_nonprofit_criteria.cfm.

${ }^{30}$ Ibid.

31 ISO (2015). ISO 9000 Quality management systems - Fundamentals and vocabulary, ISO, Geneva, Switzerland.

${ }^{32}$ Ibid.
} 
conceptualization and implementation is indeterminate or ambiguous ${ }^{33}$. In the sector of education, the prevailing quality practices are fragmented and inconsistent; even top universities have not necessarily explicit professional understanding or creative implementation for quality, or they follow obsolete approaches. Difficulties for the universities' quality management include:

- Basic professional concepts of quality, quality management, quality improvement and quality assurance are not well-known although they are widely used in all other business sectors globally and even are internationally standardized.

- Quality approaches in the universities - for instance according to the Bologna process $^{34}$ - are based on old-fashioned formal quality assurance systems and external control for conformity, which easily causes confusion and leads to stagnation. Need of methodological improvement has been recognized, but the consequential development has not yielded established results ${ }^{35}$.

- The universities' quality considerations normally focus only on the education and do not cover the areas of research and social collaboration. However, all these three areas are very closely related to each other and they should be considered as a whole. This is particularly essential in the smart city projects.

- Many universities have not specific quality related education programs or research activity.

- Many universities do not have well established general managerial practices and culture that does not support effective integration of quality into the management processes.

- How to behave in competitive situations, is not familiar to universities.

- Universities are societal institutions, and their operation and development depend on decisions of those in power in the society.

- Ontological and epistemological bases of teaching/learning/collaborating and quality are not linked with the quality realization and evaluation.

- Prevailing academic evaluation culture of student and university scoring is not aligned with the quality related evaluations.

The basic concepts of quality, quality management, quality improvement and quality assurance ${ }^{36}$ are essential prerequisites for professional realizing and implementing quality practices in the universities. The internationally standardized definitions of the concepts are beneficial also in the educational sector, but they should be understood in the university context. Benchmarking with the organizations outside the educational sector could provide new ideas for the development of the universities but is not generally practiced.

According to its definition ${ }^{37}$, the essence of the concept of quality is the perception of satisfaction of all stakeholders of the university. Especially both teachers and students should perceive the educational processes valuable. Hence the key challenge for quality in education is to recognize and fulfill the needs and expectations of students and teachers, and other stakeholders involved with the university services. The general quality definition is valid for the university environments, but the

\footnotetext{
${ }^{33}$ Anttila, J. and Jussila, K. (2015). Striving for the 'Quality society' through high quality education and lifelong learning, 59th EOQ Congress, Athens, Greece.

${ }^{34}$ EURASHE (2015). Standards and Guidelines for Quality Assurance in the European Higher Education Area (ESG). Brussels Belgium. https://www.eqar.eu/fileadmin/documents/bologna/ESG_2015.pdf.

${ }^{35}$ PHExcel Consortium (2014). Quality tools for professional higher education review and improvement, Eurashe, Brussels Belgium. http://files.eurashe.eu/library/quality-

he/PHExcel_Quality\%20Tools\%20for\%20PHE\%20Review\%20and\%20Improvement_2014.pdf.

${ }^{36}$ ISO (2015). ISO 9000 Quality management systems - Fundamentals and vocabulary, ISO, Geneva, Switzerland

${ }^{37}$ Ibid.
} 
challenge is to understand and describe its meaning in the composite situation of education, research and societal collaboration. The needs and expectations of the different stakeholders cannot be standardized, nor even easily identified. For the purposes of the smart cities the concept of quality should be understood in broad sense including sustainability and quality of society and the large variety of the characteristic dimensions of the smart cities ${ }^{38}$.

Quality management implies coordinated activities to direct and control the organization and its processes with regard to quality. Hence realization of the quality originates in the organization's management processes.

Quality improvement is to increase the ability to fulfill the needs and expectations of the stakeholders and hence it is a key element of the professional quality management. It actually is based on individual and organizational learning and innovation in the organization.

The purpose of quality assurance is to provide the stakeholders with factual information when an organization needs to demonstrate its ability to provide outputs that fulfill requirements and aim at enhancing stakeholder satisfaction. Also quality assurance is a part of quality management.

\section{Universities as manageable systems for quality and excellence}

High quality does not take place accidentally, but it needs a professional approach and coherent quality realization in the management and operational processes of the university and its units. Starting point for the systematic quality development is to identify the university entity and its units as organizational systems and recognize the organizational context including external and internal issues that are relevant to the purpose and strategic direction and that affect the ability to achieve the intended results of quality ${ }^{39}$.

The framework model ${ }^{40}$ of figure 1 can be used for the comprehensive quality management approach in the universities covering all organizational functions and units.

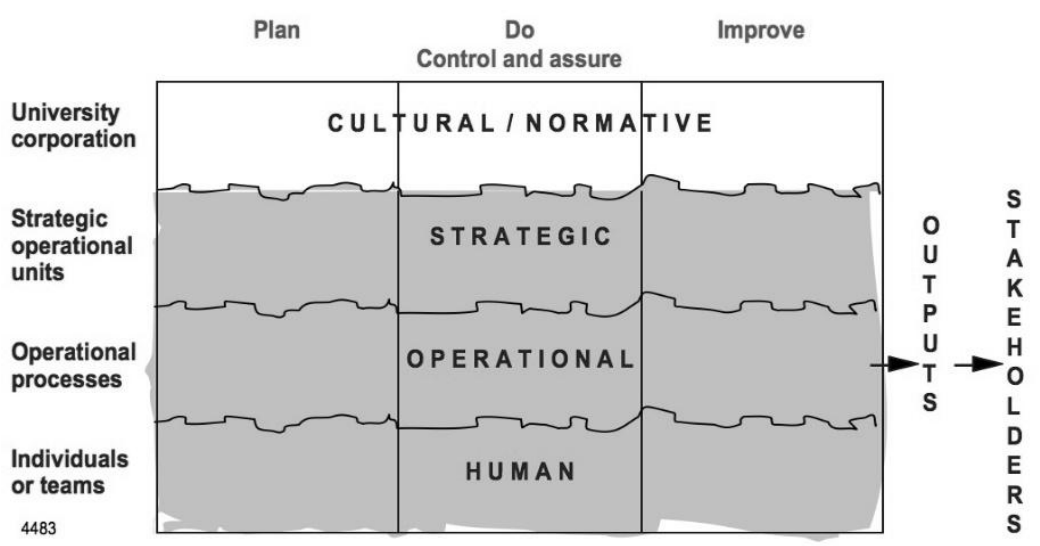

Figure 1. General management framework for the university corporation consisting of different kinds of competence, responsibility and practices, and learning needed at the different organizational levels of the university. Quality related planning, doing and improving are needed at all levels.

\footnotetext{
${ }^{38}$ Anttila, J. and Jussila, K. (2015). Striving for the 'Quality society' through high quality education and lifelong learning, 59th EOQ Congress, Athens Greece.

${ }^{39}$ ISO (2015). ISO 9001 Quality management systems - Requirements, ISO, Geneva Switzerland.

${ }^{40}$ Anttila, J. (2007). A creative business-integrated application of the ISO 9000 standards in Sonera Corporation, Finland, Moosa,

K. and Shariff. I. (Eds.), Practical guide to ISO 9000:2000 Quality management system, Ibrahim Publishers, Lahore Pakistan.
} 
This model covers the following four organizational levels:

- The normative and cultural level (the university corporation), where the general principles, the university-wide common insight, goals, shared tools, policies and practices concerning quality are created, including how these are to be applied in practice on the basis of the whole university's needs. Responsibility belongs to the top management. It cannot be delegated.

- The strategic level (strategic units of the university), where decisions are made by the management of the unit, and measures undertaken concerning the entire unit's activities and especially the future competitiveness of the unit. The unit's operational system is composed of the interrelated operational processes. Different units may have different needs but all units operate within one culture of the university.

- The operational level (operational processes), where decisions and measures concerning daily management are made and undertaken, and products (goods and services) are realized in real time for stakeholders' needs, just 'now and here'. Responsible person is the process owner.

- The human level (people and teams), where the personal contribution of each member of the organization's personnel (including managers) is provided in natural working environments. Responsibility is on the person him/herself.

Based on the framework of the figure 1, the different possibilities of the universities being involved with the smart city project(s) include (a) the visionary efforts of the entire university and possibly external funding arrangements for the research, (b) the strategic and operational activities of certain faculties of university departments, or (c) the involvement of the individual researchers or research teams for their own interest or merit. The last option is typical in Finland. The university researchers generate results, which are useful to be applied for the smart city development either directly or via different organizations, especially SMEs, that are involved with smart city projects. The researchers themselves are not necessarily directly engaged with the smart city project.

Quality is a specialized competence that should be taken into account at all levels of the university corporation, including normative, strategic, operational and human viewpoints. Quality management measures at all these levels should be aligned. Professional and exemplary quality approach is to ensure the effective collaboration with other organizations and sustained success of the university in its activities ${ }^{41}$.

\section{Strategic intention and direction to the smart city development}

The smart city development consists of many very different areas of special expertise, including citizenship, governance, education, healthcare, security, buildings, infrastructure, transportation, mobility, energy, and technology, and it requires long term efforts. Hence, the large scale smart city orientation should be based on a strategic decision of the university or its strategic units. In addition, it is necessary that the university people collaborate with other universities and different kinds of other organizations.

Traditionally universities have cooperated with public organizations and private companies in research and development projects, which have aimed at beneficial results to the business of the external partners, the universities' own educational ${ }^{41}$ ISO/TC 176/SC2 (2017). Working drafts for the standard ISO 9004:2018 (planned), Quality of an organization - Guidance to
achieve sustained success. (Not published). 
purposes and the students for their career development ${ }^{42}$. Smart city projects, however, are more versatile projects requiring many different kinds of know-how, experience and cooperation with many different partners.

Strong smart city orientation in universities create increasing demands for skills, competences and operations to respond in new ways towards the development of the society. Particular general viewpoints that are needed in the education, research and societal activities of the university include (1) innovative and adaptive thinking, (2) virtual collaboration and social intelligence, (3) ability to work across disciplines, (4) literacy in different types of media and (5) computational thinking and analytics ${ }^{43}$. These skills are required among the university staff, but the university should also teach and promote these skills to students and partners, for instance in the smart city projects. The strength of the universities compared with the other smart city parties is that they are involved with multi-faculty education, research and industry collaboration. Hence, the university can provide many research teams of different disciplines to the smart city development.

As an example we can consider the University of Helsinki ${ }^{44}$. The University has to offer multidisciplinary educational, research and development, and co-operational services to the smart city projects for instance from the Faculty of

Science/Department of Computer Science (Information technology, 5G mobile communication, Internet of things, Information security, Artificial intelligence, etc.), Faculty of Biological and Environmental Sciences (Multidisciplinary urban research), Department of Geosciences and Geography (Urban geography and regional studies), Faculty of Social Sciences/ Department of Political and Economic Studies/The Consumer Society Research Centre (Societal structures and consumers) and Faculty of Arts/Department of Modern Languages (Narratives in urban planning, Digital humanities). Hence, the possibilities are multidisciplinary and unlimited.

Very interesting and important area in the smart city development is the human focused research, because all smart city realizations have emphasized technological aspects. However, the smart citizens ${ }^{45}$ have the crucial role in the smart city operations. The smart citizens possess interest in embracing smart and green solutions in their daily activities. More citizen proactivity is expected in adopting smart concepts and smart products, including lifestyle choices. At the University of Helsinki, these aspects are considered in the context of the digital humanities research, which also have links with the European research program SSH (Socioeconomic sciences and humanities $)^{46}$. Digitalization have strong influence on people's operations, occupations and careers, employeeship, consumption patterns and social relationships.

In the context of smart citizens, researchers and developers also should consider the 'dark side' of the digitalization and smart cities, which particularly are related to the information aspects in the smart city services and their influence on human behavior and mind development. People can be confused or misled as individuals or groups by the massive information overload, disinformation, fake news or alternative facts.

\footnotetext{
${ }^{42}$ Jussila, K. and Anttila, J. (2015). Quality management for enhancing the firm's financial performance in global operations, An example of the research and development project between university and a business company, The World Quality Forum, Budapest, Hungary.

${ }^{43}$ Lee, J. (2016). 5 key skills needed in the digital economy, https://www.linkedin.com/pulse/5-key-skills-needed-digitaleconomy-jaclyn-lee-phd?trk=mp-reader-card.

${ }^{44}$ University of Helsinki (2017). The University of Helsinki in brief, https://www.helsinki.fi/en/university/the-university-ofhelsinki-in-brief.

${ }^{45}$ Frost \& Sullivan (2013). Strategic opportunity analysis of the global smart city market, http://www.egr.msu.edu/ aesc310web/resources/SmartCities/Smart\%20City\%20Market\%20Report\%202.pdf.

${ }^{46}$ European Commission (2017). Research \& innovation, Social Sciences and Humanities, http://ec.europa.eu/research/socialsciences/index.cfm?pg=about.
} 
Threats of the information security and privacy ${ }^{47}$ can be dangerous to individuals' belongings, life and identity, because also hostile actors may exist in our societal networks. Also too strong influence of the digital environment may damage human mind, especially through addictions and the mind development of the young school children $^{4849}$.

In the field of quality, the universities could collaborate with local or international professional quality organizations and other organizations for striving for quality of society in the smart city projects. New networking and learning means ${ }^{50}$ may be used in this context.

\section{Innovative organizational solutions of the universities}

It is useful for the development of the universities for the future needs to introduce new disruptive operational practices that are not typical in the traditional university culture. Here we take as an example the Aalto University ${ }^{51}$ in Espoo, the neighboring city of Helsinki. Aalto University has also contributed to the smart city projects in Espoo and Helsinki ${ }^{52}$.

In addition to the traditional educational means in the different Aalto University's schools, the university has three 'Factories' that are flexible new university units serving as joint platforms that combine the expertise of the university schools: Design Factory, Health Factory and Media Factory. These factories are designed to facilitate new forms of collaboration in an environment where academic teams, researchers and students work together with companies and communities. The themes of teaching and learning are important parts of the factory activities - the new knowledge produced by research is smoothly transferred to teaching. For instance, the Design Factory ${ }^{53}$ has made a lot of cooperation with companies, and hence they have practical multidisciplinary projects, research and education in product development, marketing, international business, innovations and IPR (intellectual property rights). The results have been very successful, and the Design Factory concept has been expanded to many other universities everywhere in the world.

The City of Espoo has co-initiated with the Aalto University the privately run Urban $\mathrm{Mill}^{54}$, a public-private co-working and co-creation platform for urban innovations on the Aalto University campus. Urban Mill's success is demonstrated by its 50000 users and 100 prototypes since 2013. It is a powerful example of an open innovation platform that uses a thematic approach, agile orchestration and co-creation methods to advance urban change.

Aalto University also supports students' activities for creating their entrepreneurship skills. Important example is Aaltoes ${ }^{55}$ (Aalto Entrepreneurship

\footnotetext{
${ }^{47}$ Kajava, J., Anttila, J. and Varonen, R. (2008). Radio frequency identification as a challenge to informaiotn security and privacy, In Ed. Nemati, H. Information security and ethics: Concepts, methodologies, tools, and applications, pp. 3848-3855.

${ }^{48}$ Kashmanian, K. (2000), The impact of computers on schools: Two authors, two perspectives, http://technologysource.org/article/impact_of_computers_on_schools/.

${ }^{49}$ Rowan, C. (2014). 10 reasons why handheld devices should be banned for

children under the age of 12, http://www.huffingtonpost.com/cris-rowan/10-reasons-why-handheld-devices-should-bebanned_b_4899218.html.

${ }^{50}$ Anttila, J. (2008).Advanced Web 2.0 based interactive technology to support informal learning for enhancing quality of business management, ICELW conference, New York USA.

${ }^{51}$ Aalto University (2017). http://www.aalto.fi/en/.

${ }^{52}$ Hertell, S. (2016). Espoo Innovation Garden: Northern hotspot of youth, innovation and startups,

http://cor.europa.eu/rie/Pages/story-9.aspx.

${ }_{53}$ Aalto Design factory (2017). Educating the world's best product designers, http://designfactory.aalto.fi/.

${ }^{54}$ Urban Mill (2016). Urban Mill - Building IntenCity! Co-working and Co-creation Platform Prototype for Urban Innovations -

Entrepreneurial Thought in Action! https://urbanmill.org/english/.

${ }_{55}$ Aaltoes (2017). https://aaltoes.com/.
} 
Society), which is the largest and most active student-run entrepreneurship community in Europe. Particularly interesting area, where Aaltoes is active, is the Startup activity including the concepts of Startup Sauna ${ }^{56}$ and Startup Life. The success of the Startup Sauna's activities is the annual Slush ${ }^{57}$ event in Helsinki that for instance in 2016 gathered together 17500 attendees, 2300 startups, 1100 investors and 600 journalists from all over the world.

These new operational modes of the university are not particularly directed to smart city projects, but many of their research and development topics are relevant from the different features of the smart cities.

Many smart city parties are small organizations or startups born in university environments. Established quality management methodology, which can be effectively integrated with the business activities of such organizations, is not yet available, hence, this topic is a part of our ongoing research and development ${ }^{58}$. Quality management of the startups and small organizations could also be an acute education and research topic in universities.

\section{University as a composite of the learning organizations for quality integration}

A university is a composite of different strategic units that can be considered as learning organizational systems. Systematic development of quality in those units means organizational learning that leads quality activities embedded into units' managerial and operational processes (figure 1). We call this Quality Integration.

A comprehensive model $^{59}$ for developing organizational quality integration towards excellence of performance is described in the diagram of figure 2. Organizations' overall existing performance depends on how well organization's people understand the governing principles (or guiding ideas) relevant to the particular organization, what kind of managerial tools and methodology they have for responding to the needs and expectations of the stakeholders, and what kind of infrastructure they have for getting the whole organization and all of its people to strive for the objectives towards the excellence goals.

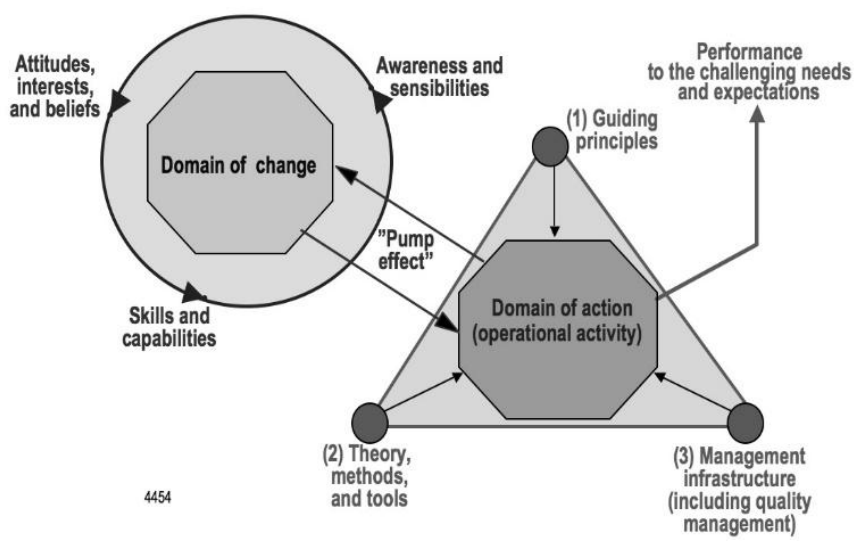

Figure 2. Foundations of the learning organization for quality integration ${ }^{60}$

\footnotetext{
${ }^{56}$ Startup Sauna (2017). http://startupsauna.com/.

${ }^{57}$ Slush (2017). Not the Californian sun but honest Slush. http://www.slush.org/about/what-is-slush/.

${ }^{58}$ Anttila, J. and Jussila, K. (2017). Out of the crisis of the quality profession: The new renaissance in the quality discipline (To be published).

${ }^{59}$ Senge, P., Roberts, C., Ross, B, and Kleiner, A. (1995). The Fifth Discipline Fieldbook: Strategies and Tools for Building a

Learning Organization. Nicholas Brealey Publishing Limited, London UK.

${ }^{60}$ Ibid.
} 
In order to get better performance, the organization should establish a process to change and improve the existing guiding ideas, tools and methodologies, and the business management infrastructure (The 'Pump effect' in the figure 2). That particularly means to find new awareness, to change attitudes and beliefs, and to create new skills and competences within the organization.

Awareness, attitudes, skills and competences develop in organizations through organizational learning. Incremental learning is related to certain particular skills representing different disciplines that are needed for the improved operations. Radical discontinuous change in the development is a strategic transformation process. Genuine transformation often requires a crisis. In strategic crisis there is a need for a large-scale breakthrough change in organization's structure and processes.

Transformation means a change of form, shape or appearance. Basically it is a mental conversion, because crises actually are in human minds. Transformations are initiated and managed from the strategic management level of the organization. Organizational transformations do not happen spontaneously or at random but by decisive actions and include consistent learning and innovations, too. Diffusion of the awareness, knowledge and skills of specialized disciplines within the organization requires personal mastery, mental models, shared vision, team learning and systems thinking that are important in creating new integration in an organization.

\section{Evaluation of the university quality}

Performance evaluation is a traditionally central issue of established quality management. Many different evaluating practices have been developed for formal educational systems and learning results, which have been used at different educational institutions nationally and internationally ${ }^{61}$. These approaches typically focus on distinct performance aspects and are not consistently compatible and may be confusing from the holistic or quality perspective.

Quality related evaluations can apply to quality, quality management, quality improvement and quality assurance, which differ from each other in terms of purpose and methodology. The evaluations should cover universities' all activity areas, including education, research and social collaboration. Evaluation of the effectiveness and efficiency of the organizational systems and processes of the university is fundamentally different from the evaluation of the students' and teachers' perception, which relates to human aspects. For quality management purposes evaluations should primarily be made by the organization itself.

All evaluations should base on sound epistemological and metrological foundations $^{62}$. Metrology is the science of measurement and its application, and the vocabulary of metrology covers the generally accepted terms and definitions for the whole topic and for all areas of activity. Measurement means experimentally obtaining one or more quantity values that can reasonably be attributed to a quantity of the item as the object of the measurement. One should make clear in a practical way the meanings and roles of the concepts like fact, data, information, and knowledge, and how they are related to the measurement activity. There are many different purposes for the evaluations, including:

- Research for getting new knowledge of the organizational performance.

\footnotetext{
${ }^{61}$ Anttila, J. and Jussila, K. (2015). Quality evaluation of education and learning. World Quality Forum, Budapest.

${ }^{62}$ Anttila, J. and Jussila K. (2011). 'You get what you measure.' Or not? Challenges for fact-based quality management. The 12th International Symposium on Quality, 'Quality for Excellence', March 17 - 18, 2011, Osijek, Croatia, pp 347-367.
} 
- Acquisition of information for planning the university operations.

- Controlling operations and processes.

- Measurements for problem solving and performance improvement.

- Measurements for quality assurance.

The most important purposes of the evaluations relate to performance improvement and quality assurance.

Recognized evaluation related practices for educational institutions from quality point of view include ${ }^{63}$ :

- Monitoring, measurement, and diagnostic analysis and evaluation

- Internal audit

- Management review

- Self-assessment

These practices are not, however, well-established in practice in the educational sector.

\section{Reference guidance of quality management for universities}

One can find significant general ideas for quality integration from the rich professional quality literature, teachings of the recognized gurus of quality profession, and through benchmarking the practices of world class organizations. In addition, international standards are important references for quality management, too.

However these information sources are not well known among the educational organizations, including universities. In addition, these references unfortunately give a very fragmented understanding of the quality practices, and hence their consistent application can be difficult without reasonable theoretical and holistic professional quality know-how.

International ISO 9000 standards are the most well-known and widely used general business independent quality management standards. They have been the major references for the development of quality management approaches in all kinds of organizations globally during more than three decades. ISO 9000 standards also define the universal quality management principles that are the fundamental truths or propositions that serve as the foundation for a system of belief or behavior, or for a chain of reasoning for the standardized approach of the quality management. ISO 9000 basic standards series consist of three standards, ISO $9000^{64}$, ISO $9001^{65}$ and ISO $9004^{66}$, considering terminology, requirements and guidance for quality management. These standards are well applicable in a creative way also in the universities.

The education specific standard ISO $21001^{6768}$ (now at the draft stage) will challenge all educational organizations, because it requires the adoption of the general basic quality concepts and quality management structures and practices. The standard will enable educational organizations to demonstrate their ability to provide consistent education and hence to increase the credibility of the organization and enhance

\footnotetext{
${ }^{63}$ ISO/PC 288 (2016). ISO/CD 21001 Educational organization management systems -- Requirements with guidance for use (Draft).

${ }^{64}$ ISO. ISO 9000 Quality management systems - Fundamentals and vocabulary, ISO, Geneva, Switzerland, 2015.

${ }^{65}$ ISO. ISO 9001 Quality management systems - Requirements, ISO, Geneva, Switzerland, 2015.

${ }^{6666}$ ISO/TC 176/SC2 (2017). Working drafts for the standard ISO 9004:2018 (planned), Quality of an organization - Guidance to achieve sustained success. (Not published).

${ }^{67}$ ISO/PC 288. ISO/CD 21001 Educational organization management systems -- Requirements with guidance for use (Draft), 2016.

${ }^{68}$ Anttila, J. and Jussila, K. Quality management in educational organizations, International Conference 'Lifelong Learning: Continuous Education for Sustainable Development', St.Petersburg, Russia, 2016.
} 
satisfaction of the stakeholders of the educational organizations. Unfortunately this standard focus only on the area of education but does not consider the two other areas of the university activities.

The American Baldrige Excellence Framework (Education) ${ }^{69}$ is a leadership and performance management framework for the education sector that empowers the educational organization to accomplish its mission, improve results, and become more competitive. This framework model is particularly useful for self-assessments of the overall performance of the educational organizations. The framework includes:

- The education criteria for performance excellence covering critical aspects of achieving excellence throughout the organization

- The core values and concepts (beliefs and behaviors found in high-performing organizations)

- Guidelines for responding to the education criteria and evaluating and scoring processes and results

\section{Conclusions}

Quality is a general recognized professional discipline with more that 100 years modern successful evolution. Quality is imperative in all educational institutions, and also the universities should for their benefits follow quality principles and practices that are applied globally in all kinds of organizations of our societies. This applies to all activity sectors of the universities including the composite activities of education, research and societal collaboration. They also should act as advanced quality role models and scientifically and educationally contribute to the development and disseminating quality philosophy and methodologies widely in the society. This however requires strive for excellence in the universities' own development of quality integration.

Smart cities aim at the effective integration of physical, digital and human systems in the built environment to deliver a sustainable, prosperous and inclusive future for its citizens. Smart city projects are taking place everywhere in the world through collaboration of many public and private organizations. Participation in these projects is a big challenge for universities, where their strengths are multidisciplinary activity in education, research and societal cooperation.

\footnotetext{
${ }^{69}$ NIST (National Institute for Standards and Technology) (2015). Baldrige Excellence Framework (Education). https://www.nist.gov/baldrige/publications/baldrige-excellence-framework/education
} 